\title{
INTRODUCTION
}

\section{INFERENCE AND DECISION MAKING}

\author{
JOHN GEWEKE, ${ }^{\mathrm{a}}$ JOHN RUST ${ }^{\mathrm{b}}$ AND HERMAN K. VAN DIJK ${ }^{\mathrm{c} *}$ \\ ${ }^{a}$ Department of Economics, University of Iowa, Iowa City, IA 52242-1000, USA \\ ${ }^{\mathrm{b}}$ Department of Economics, Yale University, PO Box 208264 Yale Station, New Haven, CT 06520-8264, USA \\ ${ }^{\mathrm{c}}$ Econometric Institute, Erasmus University Rotterdam, Burg. Oudlaan 50, Rotterdam, NL-3062 PA, The Netherlands
}

A major focus of applied econometric work is decision making in the context of uncertainty. Sometimes this work is several steps removed from the actual decision. For example, it may entail providing information in a form more suited to decision making, or reducing the uncertainty in the decision-making environment.

Increasingly, applied econometricians are becoming more directly involved in decision making. The quality and quantity of data available are increasing, while the costs of accessing and using these data are diminishing rapidly. Both public and private sector decision makers are embracing formal methods to measure and control the impact of uncertainty. In this context the incentive to develop and apply econometric tools that use data to better inform decision-making is great. Applied econometricians have responded with new methodologies and with more direct attention to the problems that confront decision makers.

In June 1999 the editors of this issue sponsored a conference on Inference and Decision Making that convened in Rotterdam. The meeting brought together about forty authors and discussants, and focused on seventeen papers responding to the demand for better informing decisions with econometric methods. From the presentation and discussion at the meeting and through subsequent review and revision, the eight articles that comprise this issue were selected.

These articles reflect the diversity of decisions that applied econometricians are called upon to inform, and the array of tools that they use in attacking these problems. Five contributions are concerned with public policy decisions. Four of these are related to employment and the labour force. Aico van Vuuren, Gerard van den Berg and Geert Ridder study the impact of the dispersion in unemployment benefits on labour supply, recognizing that wages and productivity levels also vary across jobs and individuals. Yannis Bilias examines the effect of alternative supplements to unemployment insurance on the propensity for returning to work. Todd Stinebrickner models the relationship between the wage structure for public school teachers in the United States and the rate at which they leave teaching for other occupations. Gary Chamberlain studies the persistence in individual earnings beyond that which can be accounted for by age and education. Frank Schorfheide takes up the situation of a monetary authority or macroeconomic policy

*Correspondence to: Herman K. van Dijk, Econometric Institute, Erasmus University, Rotterdam, Burg. Oudlaan 50, Rotterdam, NL-3062 PA, The Netherlands. e-mail: hkvandijk@few.eur.nl

Copyright (C) 2000 John Wiley \& Sons, Ltd. 
maker who must make day-to-day decisions in the face of competing alternative views of aggregate behaviour.

The remaining three articles address decisions made in the private sector. Charles Bos, Ronald Mahieu and Herman van Dijk take up the risk management problem of the financial officer of a firm dealing in multiple currencies. Mardi Dungey, Vance Martin and Adrian Pagan examine the optimal portfolio decision of an international investor dealing in the long-term bonds of several countries. Richard Paap and Philip Hans Franses predict the impact of promotions on individual shoppers' subsequent selection of alternative brands of the same product.

The diversity of data sets in these articles is striking. Panel data is central to the contributions by van Vuuren et al., Stinebrickner, Chamberlain, and Paap and Franses. Schorfheide uses aggregate time series. A focus of the contribution from Bilias is the use of data from an experiment that has been interrupted. The articles by Bos et al. and Dungey et al. draw on the very rich base of financial data that has grown both extensively and intensively in recent years.

Chamberlain and Schorfheide use formal Bayesian methods, and address some foundational questions raised by the decision-making environment. Bos et al. and Paap and Franses also apply formal Bayesian methods, and exploit recent developments in Monte Carlo for their implementation. Stinebrickner and Van Vuuren et al. apply structural maximum likelihood methods. Bilias uses classical statistical methods to account for the impact of interruption on experimental data. Dungey et al. use indirect estimation to cope with latent variables.

None of these articles could have been written a few years ago. Each reflects a melding of ongoing methodological innovations, improvements in data collection, and advances in economic theory, all designed to better address important decision-making problems in the public and private sectors.

\section{ACKNOWLEDGEMENTS}

Financial support from the Econometric Institute, Erasmus University Rotterdam; the Tinbergen Institute; Erasmus Center for Financial Research and the Journal of Applied Econometrics is gratefully acknowledged. 